\title{
Associations between hepatitis B virus basal core promoter/pre-core region mutations and the risk of acute-on-chronic liver failure: a meta-analysis
}

\author{
Feishu $\mathrm{Hu}^{1}$, Sheng $\mathrm{Bi}^{1}$, Huadong Yan ${ }^{2}$, Yu Shi ${ }^{1}$ and Jifang Sheng ${ }^{1 *}$
}

\begin{abstract}
Background: Several studies have suggested a relationship between hepatitis B virus (HBV) basal core promoter/ pre-core mutations and HBV-induced acute-on-chronic liver failure (ACLF). Therefore, we evaluated this potential relationship using a meta-analysis.

Methods: Chinese or English studies from 1966 to January 31, 2014 were included in the analysis. A random or fixed-effects model was used to merge the odds ratios (ORs).

Results: We identified 31 case-control studies containing a total population of 1995 ACLF and 3822 chronic hepatitis B (CHB) patients. Several mutations were significantly correlated with ACLF: T1753V (1.889, $95 \%$ confidence interval (Cl) [1.357-2.631]), A1762T (2.696 [2.265-3.207]), G1764A (3.005 [2.077-4.347]), A1762T/G1764A (2.379 [1.519-3.727]), C1766T (1.849 [1.403-2.437]), T1768A (2.440 [1.405-3.494]), A1846T (3.163 [2.157-4.639]), G1896A (2.181 [1.800-2.642]), G1899A (3.569 [2.906-4.385]) and G1896A/A1762T/G1764A (1.575 [1.172-2.116]). Additionally, HBeAg-negative status was also statistically significant for the progression to ACLF (OR $=2.813,95 \% \mathrm{Cl}=2.240-3.533, p<0.001)$. However, there was no association between ACLF development and HBV genotype.
\end{abstract}

Conclusions: The HBV basal core promoter/pre-core mutations T1753V, A1762T, G1764A, C1766T, T1768A, A1846T, G1896A and G1899A, and an HBeAg-negative status correlate with an increased risk of HBV-ACLF.

Keywords: Hepatitis B virus, Mutation, Acute-on-chronic liver failure, Hepatitis B e antigen

\section{Background}

Acute-on-chronic liver failure (ACLF) occurs when liver function is suddenly compromised as a result of an incident [1]. In 2009, the Asia-Pacific Association for the Study of the Liver (APASL) recommended the following definition for ACLF: acute hepatic damage showing coagulopathy and jaundice, with encephalopathy and/or ascites within 4 weeks, whether or not the patient had been diagnosed with a chronic liver disease [2]. The majority of Chinese ACLF patients showed HBV-induced hepatitis $[3,4]$. Although the biological pathways that mediate HBV infection and cause liver failure remain unknown, studies suggest that mutations in the HBV

\footnotetext{
* Correspondence: shengji.fang@163.com

'State Key Lab of Diagnostic and Treatment of Infectious Diseases,

Collaborative Innovation Center for Diagnosis and Treatment of Infectious Disease, The First Affiliated Hospital of Medical School, Zhejiang University, Hangzhou 310000, China

Full list of author information is available at the end of the article
}

viral genome may play a role in the progression of liver diseases [5-8]. HBV mutations in the basal core promoter $(\mathrm{BCP}) /$ pre-core $(\mathrm{PC})$ regions are relatively well understood [9-11]. BCP mutations lead to enhanced HBV replication in vitro, while PC mutations break the immune tolerance of chronic HBV infection by inhibiting hepatitis B e antigen ( $\mathrm{HBeAg}$ ) translation [9-11]. Therefore, it is important to better understand the relationship between HBV mutations and ACLF, which may have clinical utility. Several studies have shown that $\mathrm{HBV}$ mutations in the $\mathrm{BCP}$ or $\mathrm{PC}$ regions are related to the risk of ACLF, although the sample size and the mutational sites tested were limited. Therefore, we performed a meta-analysis to quantitatively evaluate data from several available studies and investigated the relationship between $\mathrm{HBV} \mathrm{BCP} / \mathrm{PC}$ variations and the risk of developing ACLF. 


\section{Results}

Search results

We identified 2790, 831, 25 and 15 articles from the PubMed, EMbase, Biomed Central and ClinicalTrials databases, respectively. The four primary Chinese databases used were: Chinese Biological Medicine, WANFANG DATA, VIP and China National Knowledge Infrastructure, which yielded 889, 1564, 1011 and 1303 studies, respectively. This approach resulted in 3478 and 2203 studies after removing duplicates from English and Chinese databases, respectively. After title screening (4908 not relevant to HBV mutation or liver failure, 310 associated with human immunodeficiency virus (HIV) or hepatitis C virus), 463 potential articles remained, which were reduced to 61 after reviewing abstracts (338 were not related to mutations, 35 not related to ACLF and 29 related to hepatocellular carcinoma [HCC]). In addition, 30 articles were removed after completing a full text scan (17 lacked control groups, 5 participants were co-infected with other hepatic viruses, 2 were co-infected with HIV and 6 had HCC). We included 31 articles in our meta-analysis (Fig. 1).

\section{Characteristics of trials included in this meta-analysis}

The 31 trials were all case-control trials from China. The primary mutation detection method was nested polymerase chain reaction and sequencing. The quality of the studies on the Newcastle-Ottawa Scale (NOS) scale was between 5 and 7 (see Additional file 1: Table S1). There were $5817 \mathrm{HBV}$ patients, 1995 of whom had ACLF. The most common mutations in the $\mathrm{BCP} / \mathrm{PC}$ regions that were associated with ACLF progression were T1753V, A1762T/G1764A, A1762T, G1764A, C1766T, T1768A, A1846T, G1862T, G1896A, G1899A and G1896A/A1762T/G1764A (Table 1).

\section{Patient characteristics}

The studies that were included in this meta-analysis compared patients with ACLF and patients with CHB of different severities (mild, moderate and severe), or CHB patients without differentiating by severity. There were mostly males in both the ACLF and CHB groups, and the main genotypes were $B$ and $C$. There were significantly fewer ACLF HBeAg-positive patients than $\mathrm{HBeAg}$-negative patients, while the opposite was seen in the CHB group (Table 2).

\section{Data synthesis}

\section{Overall risk estimates}

The risk assessment for ACLF patients with the mutations of interest in the individual trials is summarized in Additional file 2: Table S2 and Fig. 2. Overall, the following mutations were found to be meaningfully related to ACLF risk (shown as summary OR and $95 \%$ [CI]): T1753V (1.919 [1.414-2.606]), A1762T (2.685 [2.2643.185]), G1764A (2.901 [2.041-4.122]), A1762T/G1764A double mutation (2.376 [1.548-3.648]), C1766T (1.849 [1.403-2.437]), T1768A (2.199 [1.563-3.094]), A1846T (3.163 [2.157-4.639]), G1896A (2.181 [1.800-2.642]), G1899A (3.525 [2.882-4.312]) and G1896A/A1762T/ G1764A triple mutation (1.575 [1.172-2.116]). G1862T was not significantly associated with ACLF risk, but when we removed the study conducted by Xiaoqiang Ren, statistical significance was achieved (summary $\mathrm{OR}=2.579$ [1.510-4.405], $p=0.001)$.

\section{Subgroup analysis}

We evaluated two subgroups, one matched by only patient age and sex, and the other matched by HBV genotype and DNA load, age and sex. The summary OR of ACLF risk for several variations was lower in matched subgroups than that in unmatched subgroups, such as T1753V, A1762T, G1764A, C1766T, G1896A, G1899A and A1846T, while an opposite result was observed for A1762T/G1764A and T1768A (Table 3).

\section{Prediction of $A C L F$ by $H B V$ mutation}

We evaluated mutation frequency as a possible biomarker to predict ACLF. Most of the mutation sites showed low sensitivity and relatively high specificity, except A1762T, which had a sensitivity of $74.5 \%(95 \% \mathrm{CI}=71.9-76.9 \%)$ and specificity of $45.8 \%$ (95\% CI = 43.7-47.9\%). G1764A showed a high positive prediction value (PPV; $80.1 \%$, $95 \%$ CI, 77.7-82.4; Table 4).

\section{HBV genotype and HBeAg status}

The summary OR of HBeAg-negative was 2.813 (95\% CI [2.240-3.533], $p<0.001)$. However, there was no evidence indicating that the HBV genotype B was significantly related to ACLF (Fig. 3), although we found that this result was unstable using a sensitivity analysis of the following studies: Aiming Zhang, Xiaodong Li, Zhengang Zhao, Xiaoyan Ma, Mingxian Zhou and Tao Yan. When these studies were removed, the summary OR $p$ value was less than 0.05 , indicating that more studies were needed to determine the relationship between $\mathrm{HBV}$ genotypes and ACLF development.

\section{Assessment of within-group heterogeneity, publication bias and sensitivity analysis}

There was a large amount of heterogeneity between different trials for T1753V, G1764A, A1846T, G1862T, G1896A and A1762T/G1764A. We therefore conducted a sensitivity analysis using a "leave one out" approach and Egger's testing, and found that these mutations were not influential, except for G1862T. Except for those with G1764A and G1896A/A1762T/G1764A, we did not observe any publication bias with T1753V, A1762T, A1762T/G1764A, C1766T, T1768A, A1846T, G1862T, G1896A or G1899A, (Table 5 and Fig. 4). 


\section{PRISMA 2009 Flow Diagram}

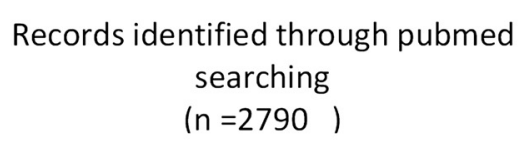

Records identified through pubmed searching

( $n=2790$ )

Additional records identified through other sources ( $n=5638$ )

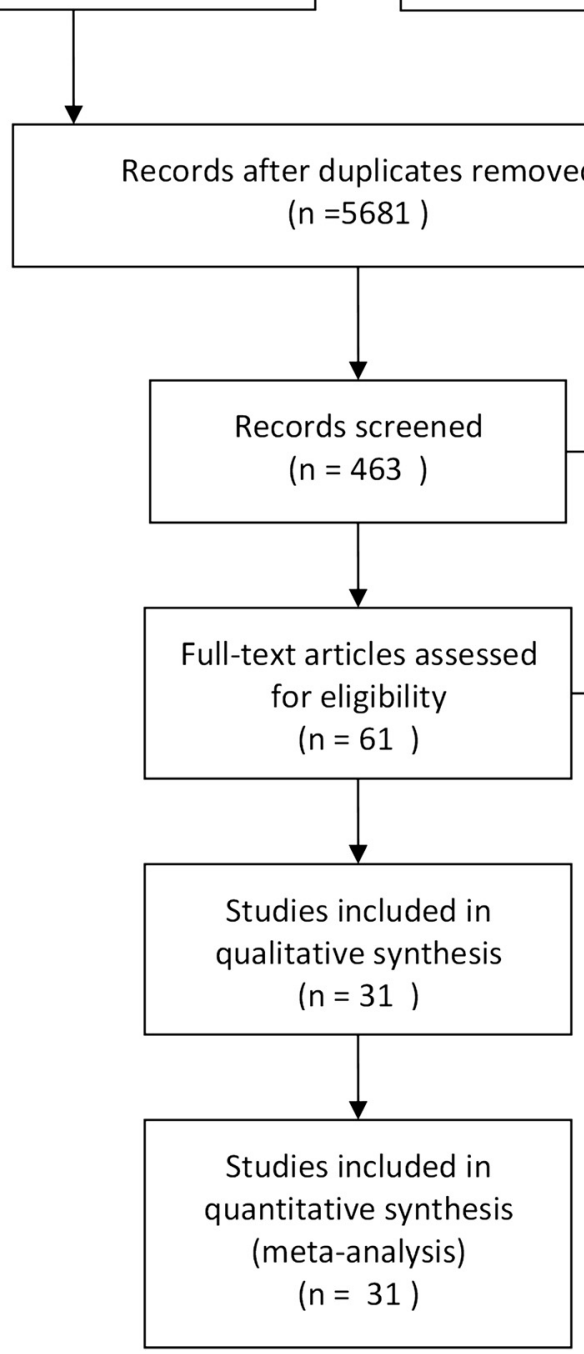

Records excluded

$(n=402)$
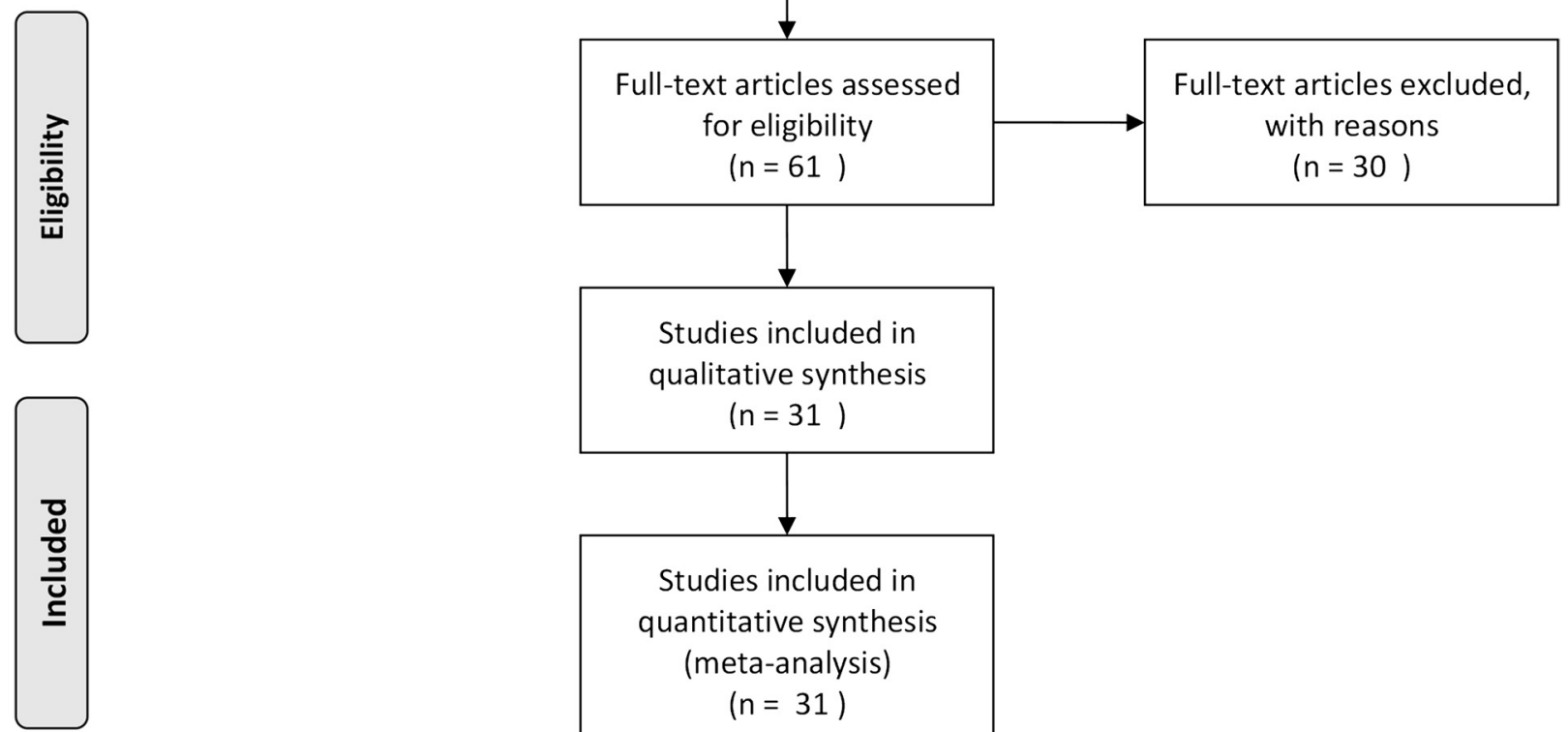

Fig. 1 Flow chart of article selection

\section{Discussion}

Our meta-analysis showed that T1753V, A1762T, G1764A, A1762T/G1764A, C1766T, T1768A, A1846T, G1896A, G1899A and G1896A/A1762T/G1764A were all related to increasing the risk of HBV-ACLF by a factor of 1.919 , $2.685,2.901,2.376,1.849,2.199,3.163,2.181,3.525$ and 1.575 , respectively.
To further confirm these results, several significant confounders were matched. Age and sex have been shown to influence progression of high-level hepatic diseases in $\mathrm{CHB}$ patients [12]. A high HBV DNA copy number may independently accelerate progression of hepatocirrhosis and HCC [13, 14]. Additionally, compared with genotype B, genotype $\mathrm{C}$ was related to more aggressive hepatic 
Table 1 Main characteristics of included trials

\begin{tabular}{|c|c|c|c|c|c|c|c|c|}
\hline \multirow[t]{2}{*}{ Study } & \multirow[t]{2}{*}{ NCA } & \multirow[t]{2}{*}{$\mathrm{NCO}$} & \multirow[t]{2}{*}{ Mutation site } & \multirow[t]{2}{*}{ Detection method } & \multicolumn{4}{|c|}{ Matching factors } \\
\hline & & & & & Age & Sex & Genotype & HBV DNA \\
\hline Aiming Zhang, 2013 & 29 & 52 & $\begin{array}{l}\text { T1753V, A1762T, G1764A, A1762T/G1764A, } \\
\text { A1846T, G1896A, G1899A }\end{array}$ & $\mathrm{NP}, \mathrm{AS}$ & + & + & + & + \\
\hline Aiming Zhang2, 2013 & 58 & 51 & $\begin{array}{l}\text { T1753V, A1762T, G1764A, A1762T/G1764A, } \\
\text { A1846T, G1896A, G1899A }\end{array}$ & $N P, A S$ & + & + & + & + \\
\hline Lei Xiao, 2013 & 77 & 136 & $\begin{array}{l}\text { T1753V, A1762T/G1764A, C1766T, T1768A, } \\
\text { A1846T, G1862T, G1896A, G1899A }\end{array}$ & $\mathrm{NP}, \mathrm{AS}$ & + & + & - & - \\
\hline Xiaodong Li, 2013 & 146 & 239 & $\begin{array}{l}\text { T1753V, A1762T/G1764A, C1766T, T1768A, } \\
\text { A1846T, G1896A, G1899A }\end{array}$ & $\mathrm{NP}, \mathrm{AS}$ & + & + & - & - \\
\hline X Ren, 2010 (40) & 75 & 328 & $\begin{array}{l}\text { T1753V, A1762T, G1764A, C1766T, T1768A, } \\
\text { G1896A, G1899A }\end{array}$ & $N P, A S$ & + & + & + & + \\
\hline Zhihui Xu, 2010 & 298 & 495 & $\begin{array}{l}\text { T1753V, A1762T, G1764A, C1766T, T1768A, } \\
\text { G1862T, G1896A, G1899A }\end{array}$ & $\mathrm{NP}, \mathrm{AS}$ & + & + & + & - \\
\hline Ling Yang, 2010 & 39 & 44 & A1762T/G1764A, G1862T, G1896A, G1899A & SNP, AS & - & + & + & - \\
\hline Zhengang Zhao, 2010 & 20 & 19 & $\begin{array}{l}\text { T1753V, A1762T, G1764A, A1762T/G1764A, } \\
\text { C1766T, T1768A, A1846T, G1862T, G1896A, } \\
\text { G1899A, A1762T/G1764A/G1896A }\end{array}$ & NP, DS & - & + & + & - \\
\hline Xiaoyan Ma, 2012 & 44 & 28 & $\begin{array}{l}\text { T1753V, A1762T, G1764A, A1762T/G1764A, } \\
\text { C1766T, T1768A, A1846T, G1896A, G1899A, } \\
\text { A1762T/G1764A/G1896A }\end{array}$ & $N P, S$ & - & + & + & - \\
\hline Zhiwei Li, 2002 & 13 & 10 & A1846T, G1862T, G1896A & $\mathrm{RP}, \mathrm{SA}$ & ND & ND & ND & - \\
\hline Shoubing Tang, 2005 & 30 & 30 & A1762T/G1764A, G1896A & $\mathrm{RP}, \mathrm{CS}$ & + & + & ND & - \\
\hline Yintang Jia, 2009 & 8 & 78 & $\begin{array}{l}\text { T1753V, A1762T, G1764A, A1762T/G1764A, } \\
\text { C1766T, T1768A, A1846T, G1896A, G1899A }\end{array}$ & $N P, D S$ & ND & ND & ND & - \\
\hline Ling Jiang, 2013 & 146 & 239 & A1762T/G1764A, G1896A & QPMK, DS & + & + & ND & - \\
\hline Wenjun Du, 2005 & 9 & 75 & A1762T, G1764A, G1896A & $R P, G C, S$ & ND & ND & ND & - \\
\hline Xiumei Zhou, 2009 & 80 & 80 & A1762T/G1764A, G1896A, G1899A & $\mathrm{RP}, \mathrm{GC}$ & + & + & ND & - \\
\hline Mingxian Zhou, 2004 & 22 & 56 & A1762T, G1896A & UK & ND & ND & + & - \\
\hline Xiaoqiang Ren, 2009 & 348 & 610 & $\begin{array}{l}\text { T1753V, A1762T, G1764A, A1762T/G1764A, } \\
\text { C1766T, T1768A, G1862T, G1896A, G1899A, } \\
\text { A1762T/G1764A/G1896A }\end{array}$ & $N P, A S$ & + & + & + & - \\
\hline Lei Jiang, 2010 & 26 & 78 & G1896A & $N P, R F L P$ & ND & ND & ND & - \\
\hline Jinqiang Li, 2006 & 30 & 20 & A1762T/G1764A, G1896A & $\mathrm{RP}, \mathrm{MS}$ & + & + & ND & - \\
\hline Chengyong Liu, 2007 & 34 & 186 & $\begin{array}{l}\text { A1762T/G1764A, G1896A, A1762T/G1764A/ } \\
\text { G1896A }\end{array}$ & $\mathrm{RP}, \mathrm{MGS}$ & ND & ND & ND & - \\
\hline Xinyu Liu, 2005 & 14 & 75 & $\begin{array}{l}\text { A1762T, G1764A, A1762T/G1764A, G1896A, } \\
\text { A1762T/G1764A/G1896A }\end{array}$ & LAS & ND & ND & ND & - \\
\hline Shuren Liang, 2003 & 23 & 68 & G1896A & $\mathrm{RP}, \mathrm{OAS}$ & ND & + & ND & - \\
\hline Zhidong Zang, 2007 & 17 & 81 & A1762T/G1764A & RP, LAS & ND & ND & ND & - \\
\hline Tao Yan, 2010 & 49 & 45 & $\begin{array}{l}\text { T1753V, A1762T, G1764A, A1762T/G1764A, } \\
\text { C1766T, T1768A, A1846T, G1896A, G1899A, } \\
\text { A1762T/G1764A/G1896A }\end{array}$ & $\mathrm{NP}, \mathrm{AS}$ & - & + & + & - \\
\hline Wei Guo, 2006 & 38 & 40 & $\begin{array}{l}\text { T1753V, A1762T, G1764A, A1762T/G1764A, } \\
\text { C1766T, T1768A, G1862T, G1896A, G1899A, } \\
\text { A1762T/G1764A/G1896A }\end{array}$ & $\mathrm{RP}, \mathrm{CS}$ & + & + & ND & - \\
\hline Yanhong Yu, 2008 & 25 & 98 & A1762T/G1764A & $\mathrm{RP}, \mathrm{GC}$ & $N D$ & ND & ND & - \\
\hline Guanghui Wu, 2008 & 30 & 30 & A1762T/G1764A, G1896A & RP, RFLP & ND & + & + & - \\
\hline Hangdi Xu, 2013 & 12 & 12 & A1762T, G1764A, A1846T, G1896A & $\mathrm{RP}, \mathrm{IS}$ & + & + & + & + \\
\hline Fan Li, 2008 (31) & 87 & 196 & $\begin{array}{l}\text { T1753V, A1762T, G1764A, G1862T, G1896A, } \\
\text { G1899A }\end{array}$ & $\mathrm{NP}, \mathrm{AS}$ & ND & + & ND & - \\
\hline
\end{tabular}


Table 1 Main characteristics of included trials (Continued)

\begin{tabular}{|c|c|c|c|c|c|c|c|c|}
\hline Lu Xu, 2012 & 64 & 69 & $\begin{array}{l}\text { T1753V, A1762T, G1764A, A1762T/G1764A, } \\
\text { T1768A, } \\
\text { G1862T, G1896A, G1899A, A1762T/G1764A/ } \\
\text { G1896A }\end{array}$ & $\mathrm{RP}, \mathrm{AS}$ & + & - & ND & - \\
\hline Hangdi Xu2, 2013 & 104 & 254 & A1846T, G1896A & SNP, AS & ND & - & - & - \\
\hline
\end{tabular}

necroinflammation, a more rapid rate of progression to cirrhosis and HCC development [15-17], although an association between HBV genotypes B and C and ACLF was not suggested in our study. Most mutations remained significantly associated with ACLF development in age and sexmatched groups and the association with G1896A was still significant after matching age, sex, HBV genotype and HBV DNA load. However, the summary ORs were higher in the confounder-unmatched and age- or sex-only-matched studies than in the age, sex, genotype and DNA loadmatched studies. Thus, our results suggest a significant association between $\mathrm{HBV}$ variations in $\mathrm{BCP} / \mathrm{PC}$ regions and the risks of developing ACLF.

The causal relationship between $\mathrm{HBV} \mathrm{BCP} / \mathrm{PC}$ mutations and ACLF development remains unknown. ACLF development was promoted by both acute factors (precipitating events) and chronic factors (underlying chronic liver diseases) [18]. Previous studies indicated that the role of $\mathrm{HBV} \mathrm{BCP} / \mathrm{PC}$ mutations that promote ACLF were more likely to influence the severity of chronic factors, because the mutations were detected both in $\mathrm{CHB}$ and HBV-ACLF patients. It was also reported that $\mathrm{HBV} \mathrm{BCP} / \mathrm{PC}$ variations appeared less frequently in $\mathrm{CHB}$ patients than in cirrhotic patients $[19,20]$, suggesting a process where mutations accumulate during $\mathrm{CHB}$ infection and are associated with latestage viral infection. Thus, these results suggested that patients with $\mathrm{BCP} / \mathrm{PC}$ mutations had more advanced HBV-related chronic liver diseases, and thus were more susceptible to hepatic insult and more likely to develop ACLF. Accumulating evidence suggests that mutations in the $\mathrm{BCP} / \mathrm{PC}$ region might exacerbate liver injury by affecting HBeAg expression and/or viral replication, which may in turn affect the immune response to HBV [21]. For example, Yang et al. suggested that HBeAg expression in the perinatal infection period caused immune tolerance [22]. Another characteristic of HBeAg that might accelerate chronic infection is that it may imitate the core protein to weaken the immune response caused by antibodies in infected hepatocytes [10]. When the occurrence of HBV mutants in different phenotypes disturbs the balance, the altered virus-cell relationship might activate adverse immune responses in some patients, causing massive hepatocyte necrosis.

When exploring the potential value of $\mathrm{HBV}$ variation in predicting HBV-ACLF, we found that T1753V, G1764A, C1766T, T1768A, G1899A and G1896A/A1762T/G1764A triple mutations were useful in predicting ACLF. A combination of A1762T/G1764A and G1896A showed a higher specificity than A1762T/G1764A double mutations (Table 4), suggesting that mutations that accumulate at different sites have synergistic effects in promoting the risk of HBV-ACLF. The results indicated that the above HBV mutations may be used as biomarkers for supporting the development of HBV-associated ACLF.

Our study also showed the relationship between HBeAgnegative status and the risk of ACLF using a pooled $\mathrm{OR}=2.813, p<0.001$. However this relationship was probably not independent. In G1896A patients, the concentration of serum toll-like receptor 2 (TLR2) reached a significantly higher level than in HBV-infected patients lacking G1896A [23]. In the absence of HBeAg, HBV up-regulated TLR2 expression on CD14+ cells [24]. TLR2 is a potential connection between G1896A and HBeAg-negative status.

This study had several limitations. First, all trials were observational so that unidentified confounders could not be eliminated. Second, because we searched only Chinese and English articles, selection bias based on language could not be avoided. Third, the data was insufficient to allow analysis of mutations such as G1896A/G1899A, G1896A/G1899A/ A1762T/G1764A and C1913V that were implicated in ACLF development in some studies [25-31]. Additionally, $\mathrm{HBV}$ mutations in other regions were not analyzed in the study. For example, pre-S/S region mutations were observed at an advanced stage of chronic HBV infection $[32,33]$. The pre-S deletion mutation has been reported to increase with liver disease progression [34]. In addition, pre-S/S region mutations could alter the immune response against HBV by affecting neutralization antibody epitopes [35] or cytotoxic $\mathrm{T}$ lymphocyte epitope binding affinity [36]. Thus, ongoing studies are needed to evaluate the clinical relevance of rare mutations in the $\mathrm{BCP}$ region and mutations in other regions. Fourth, the conclusions in this 
Table 2 Patient characteristics of included trials

\begin{tabular}{|c|c|c|c|c|c|c|c|c|}
\hline Trials & Group & $\mathrm{N}$ & Age, y & Gender (m/f) & Genotype (B/O) & HBeAg (P/N) & TB $(\mu \mathrm{mol} / \mathrm{L})$ & HBV DNA $(\log 101 \mathrm{U} / \mathrm{ml})$ \\
\hline \multirow[t]{2}{*}{ Aiming Zhang } & $A$ & 29 & 43.4 & $27 / 2$ & $7 / 22$ & $11 / 18$ & 330.2 & 3.86 \\
\hline & C & 52 & 42.3 & $42 / 10$ & $16 / 36$ & $32 / 20$ & NG & 4.63 \\
\hline \multirow[t]{2}{*}{ Aiming Zhang2 } & A & 58 & 47.4 & $48 / 10$ & $12 / 46$ & $26 / 32$ & 338.4 & 4.02 \\
\hline & C & 51 & 46.2 & $39 / 12$ & $8 / 43$ & $19 / 32$ & NG & 4.69 \\
\hline \multirow[t]{2}{*}{ Lei Xiao } & A & 77 & 38.2 & $70 / 7$ & $71 / 6$ & $22 / 55$ & 427.5 & NG \\
\hline & C & 136 & 36.9 & $113 / 23$ & $82 / 54$ & $79 / 57$ & 37.62 & NG \\
\hline \multirow[t]{2}{*}{ Xiaodong Li } & A & 146 & 47.4 & $119 / 27$ & $30 / 116$ & $45 / 101$ & 313.4 & 5 \\
\hline & C & 239 & 46.2 & $207 / 32$ & $52 / 187$ & $140 / 99$ & 74.4 & 5.8 \\
\hline \multirow[t]{2}{*}{ X Ren } & A & 75 & 39 & $67 / 8$ & $23 / 52$ & $29 / 46$ & 451 & 5.3 \\
\hline & C & 328 & 38 & $281 / 47$ & $54 / 274$ & 194/134 & 12.8 & 5.2 \\
\hline \multirow[t]{2}{*}{ Zhihui Xu } & A & 298 & 45.9 & $255 / 43$ & $63 / 235$ & 99/199 & 418.5 & 5.48 \\
\hline & C-M/S & 495 & $38.3 / 39.1$ & $427 / 68$ & $82 / 413$ & $261 / 234$ & $16.4 / 164.2$ & $5.26 / 5.99$ \\
\hline \multirow[t]{2}{*}{ Ling Yang } & A & 39 & 36 & $36 / 3$ & $24 / 10$ & $11 / 28$ & 353 & 5.75 \\
\hline & C & 44 & 26 & $36 / 8$ & $22 / 22$ & $36 / 8$ & NG & 9.16 \\
\hline \multirow[t]{2}{*}{ Zhengang Zhao } & A & 20 & 49.7 & $14 / 6$ & $0 / 16$ & $8 / 12$ & 287.37 & 5.82 \\
\hline & C & 19 & 40.37 & $14 / 5$ & $2 / 15$ & $14 / 5$ & 19.75 & 7.67 \\
\hline \multirow[t]{2}{*}{ Xiaoyan Ma } & A & 44 & 51.6 & $31 / 13$ & $0 / 44$ & NG & NG & NG \\
\hline & C & 28 & 38.7 & $20 / 8$ & $2 / 26$ & NG & NG & NG \\
\hline \multirow[t]{2}{*}{ Zhiwei Li } & A & 13 & 21 to 58 & $17 / 6$ & NG & NG & NG & NG \\
\hline & C & 10 & & & NG & NG & NG & NG \\
\hline \multirow[t]{2}{*}{ Shoubing Tang } & A & 30 & 21 & $25 / 5$ & NG & $13 / 17$ & NG & 1.47 \\
\hline & C & 30 & 20 & $24 / 6$ & NG & $16 / 14$ & NG & 3.29 \\
\hline \multirow[t]{2}{*}{ Yintang Jia } & A & 8 & NG & NG & NG & NG & NG & NG \\
\hline & C & 78 & NG & NG & NG & NG & NG & NG \\
\hline \multirow[t]{2}{*}{ Ling Jiang } & A & 146 & 46 & $119 / 27$ & NG & 49/97 & 313.4 & 5 \\
\hline & C-M/S & 239 & $41 / 38$ & $206 / 33$ & NG & $146 / 93$ & $42.38 / 106.54$ & $6.27 / 5.39$ \\
\hline \multirow[t]{2}{*}{ Wenjun Du } & A & 9 & NG & NG & NG & NG & NG & NG \\
\hline & C & 75 & NG & NG & NG & NG & NG & NG \\
\hline \multirow[t]{2}{*}{ Xiumei Zhou } & A & 80 & 48.6 & $108 / 72$ & NG & NG & NG & NG \\
\hline & C & 80 & & & NG & NG & NG & NG \\
\hline \multirow[t]{2}{*}{ Mingxian Zhou } & A & 22 & NG & NG & $3 / 19$ & NG & NG & 4.31 \\
\hline & C & 56 & NG & NG & $9 / 47$ & NG & NG & 4.72 \\
\hline \multirow[t]{2}{*}{ Xiaoqiang Ren } & A & 348 & 46 & $292 / 56$ & $53 / 200$ & $132 / 216$ & 255.9 & 4.55 \\
\hline & C-M/S & 610 & $38 / 35$ & $518 / 92$ & $95 / 476$ & $386 / 224$ & $12.4 / 55.4$ & $4.43 / 5.21$ \\
\hline \multirow[t]{2}{*}{ Lei Jiang } & A & 26 & NG & NG & NG & NG & NG & NG \\
\hline & C & 78 & NG & NG & NG & NG & NG & NG \\
\hline \multirow[t]{2}{*}{ Jinqiang Li } & A & 30 & 48.1 & $24 / 6$ & NG & NG & NG & NG \\
\hline & C & 20 & 43.9 & $15 / 5$ & NG & NG & NG & NG \\
\hline \multirow[t]{2}{*}{ Chengyong Liu } & A & 34 & NG & NG & NG & NG & NG & NG \\
\hline & C & 186 & NG & NG & NG & NG & NG & NG \\
\hline \multirow[t]{2}{*}{ Xinyu Liu } & A & 14 & NG & NG & NG & NG & NG & NG \\
\hline & C & 75 & NG & NG & NG & NG & NG & NG \\
\hline \multirow[t]{2}{*}{ Shuren Liang } & A & 23 & 39.71 & $18 / 5$ & NG & NG & NG & NG \\
\hline & C-Mo/M1/S & 68 & $35 / 36.1 / 35.5$ & $55 / 13$ & NG & NG & NG & NG \\
\hline
\end{tabular}


Table 2 Patient characteristics of included trials (Continued)

\begin{tabular}{|c|c|c|c|c|c|c|c|c|}
\hline \multirow[t]{2}{*}{ Zhidong Zang } & A & 17 & $N G$ & $10 / 7$ & $N G$ & NG & 342.3 & 2.25 \\
\hline & C & 81 & NG & $64 / 17$ & $N G$ & NG & 51.9 & 1.83 \\
\hline \multirow[t]{2}{*}{ Tao Yan } & A & 49 & 45.8 & $42 / 7$ & $9 / 40$ & $23 / 26$ & 312.2 & 4.88 \\
\hline & C & 45 & 33.9 & $36 / 9$ & $12 / 33$ & $36 / 9$ & 16.5 & 6.91 \\
\hline \multirow[t]{2}{*}{ Wei Guo } & A & 38 & 32.6 & $34 / 4$ & NG & $21 / 17$ & NG & 5.09 \\
\hline & C & 40 & 30.2 & $33 / 7$ & NG & $26 / 14$ & $N G$ & 5.48 \\
\hline \multirow[t]{2}{*}{ Yanhong Yu } & A & 25 & $N G$ & $N G$ & NG & $N G$ & NG & $N G$ \\
\hline & C & 98 & $N G$ & $N G$ & NG & $N G$ & NG & $N G$ \\
\hline \multirow[t]{2}{*}{ Guanghui Wu } & A & 30 & 40 & $25 / 5$ & $6 / 24$ & $\mathrm{NG}$ & $\mathrm{NG}$ & NG \\
\hline & C & 30 & 29 & $20 / 10$ & $4 / 26$ & NG & $N G$ & NG \\
\hline \multirow[t]{2}{*}{ Hangdi Xu } & A & 12 & 35 & $11 / 1$ & $10 / 2$ & $4 / 8$ & 324.9 & 6.71 \\
\hline & C & 12 & 35.7 & $10 / 2$ & $8 / 4$ & $10 / 2$ & 15.6 & 6.74 \\
\hline \multirow[t]{2}{*}{ Fan Li } & A & 87 & 45.4 & $69 / 18$ & $\mathrm{NG}$ & $27 / 60$ & 331 & 4.42 \\
\hline & C & 196 & 38.8 & $170 / 26$ & $N G$ & $130 / 66$ & 23.8 & 5.42 \\
\hline \multirow[t]{2}{*}{ Lu Xu } & A & 64 & 35.1 & $57 / 7$ & $N G$ & $31 / 33$ & 372.2 & 3.89 \\
\hline & C & 69 & 29.5 & $48 / 21$ & NG & $53 / 16$ & 46.5 & 5.49 \\
\hline \multirow[t]{2}{*}{ Hangdi Xu2 } & A & 104 & 40.9 & $91 / 13$ & $68 / 36$ & $51 / 53$ & 317.5 & 6.09 \\
\hline & C-M/S & 254 & $37.6 / 40.7$ & $186 / 68$ & $51 / 203$ & $185 / 69$ & $14.9 / 98.3$ & $6.14 / 5.77$ \\
\hline
\end{tabular}

A ACLF patient group, $C$ CHB patient group, $N$ number of subjects, $M 0$ mild, $M 1$ moderate, $S$ severe, $N G$ not given, $m / f$ male/female, $B / O$ genotype B/other genotypes, TB Total bilirubin, HBeAg hepatitis B e antigen, $P$ HBeAg positive, N HBeAg negative, PTA Prothrombin activity, ALT alanine aminotransferase, AST Aspertate Aminotransferase

article might not be universally applicable, because all the selected trials were conducted in China. Although no study has reported a direct relationship between the risk of ACLF and country or race, the distribution of HBV genotypes or quasispecies differs among countries and races. For example, the most prevalent HBV genotypes in China are B and $C$, whereas genotypes $A$ and $D$ are the most prevalent in Europe [37]. Although our analysis did not show a different association between genotype $\mathrm{B}$ or $\mathrm{C}$ and ACLF risk, it is unknown whether there was a different connection between other HBV genotypes and ACLF. Thus, this conclusion needs to be validated for countries or races where other HBV genotypes are the most prevalent. Fifth, summary ORs were not conducted in most manuscripts included in this meta-analysis and there were no adjusted ORs. Sixth, if the sample size were sufficiently large, grouping the HBV patients based on grades, such as HBV carriers, $\mathrm{CHB}$ and hepatocirrhosis, would show whether the mutations accumulated during $\mathrm{CHB}$ progressed to advanced liver diseases, including ACLF.

We discovered that $\mathrm{HBV} \mathrm{BCP} / \mathrm{PC}$ variations such as T1753V, A1762T, G1764A, A1762T/G1764A, C1766T, T1768A, A1846T, G1896A, G1899A and G1896A/ A1762T/G1764A, and HBeAg-negative status correlated with an increased risk of HBV-ACLF. Detecting these variations in $\mathrm{CHB}$ patients may help to identify those who are at a high risk of developing ACLF. However, further prospective studies are needed to confirm our findings and whether $\mathrm{HBV} \mathrm{BCP} / \mathrm{PC}$ mutations contribute directly to the development of ACLF. The effect of $\mathrm{HBV} \mathrm{BCP} / \mathrm{PC}$ mutations on host viral-specific immunity also needs to be clarified.

\section{Conclusions}

The HBV BCP/PC mutations T1753V, A1762T, G1764A, C1766T, T1768A, A1846T, G1896A and G1899A, and an $\mathrm{HBeAg-negative} \mathrm{status} \mathrm{correlate} \mathrm{with} \mathrm{an} \mathrm{increased}$ risk of HBV-ACLF.

\section{Methods}

\section{Search strategy and inclusion/exclusion criteria}

We searched PubMed using the following strategy: ("Hepatitis B virus" [Mesh]) AND "mutation" [Mesh] from January 1, 1950 to January 31, 2014. The search strategy for EMbase was "pub-date > 1994 and TITLEABSTR-KEY (hepatitis B virus), and TITLE-ABSTRKEY (mutation)". Biomed Central was searched using "hepatitis B virus (All words) in Title + Abstract + Text, and mutation (All words) in Title + Abstract + Text from 1997 to 2014". ClinicalTrials was searched with "hepatitis B virus" AND "mutation" without limitation. The main Chinese databases were searched using: Chinese Biological Medicine (1978 to January 31, 2014), WANFANG DATA (1997 to January 31, 2014), VIP (1989 to January 31, 2014), China National Knowledge Infrastructure (1994 to January 31, 2014); 


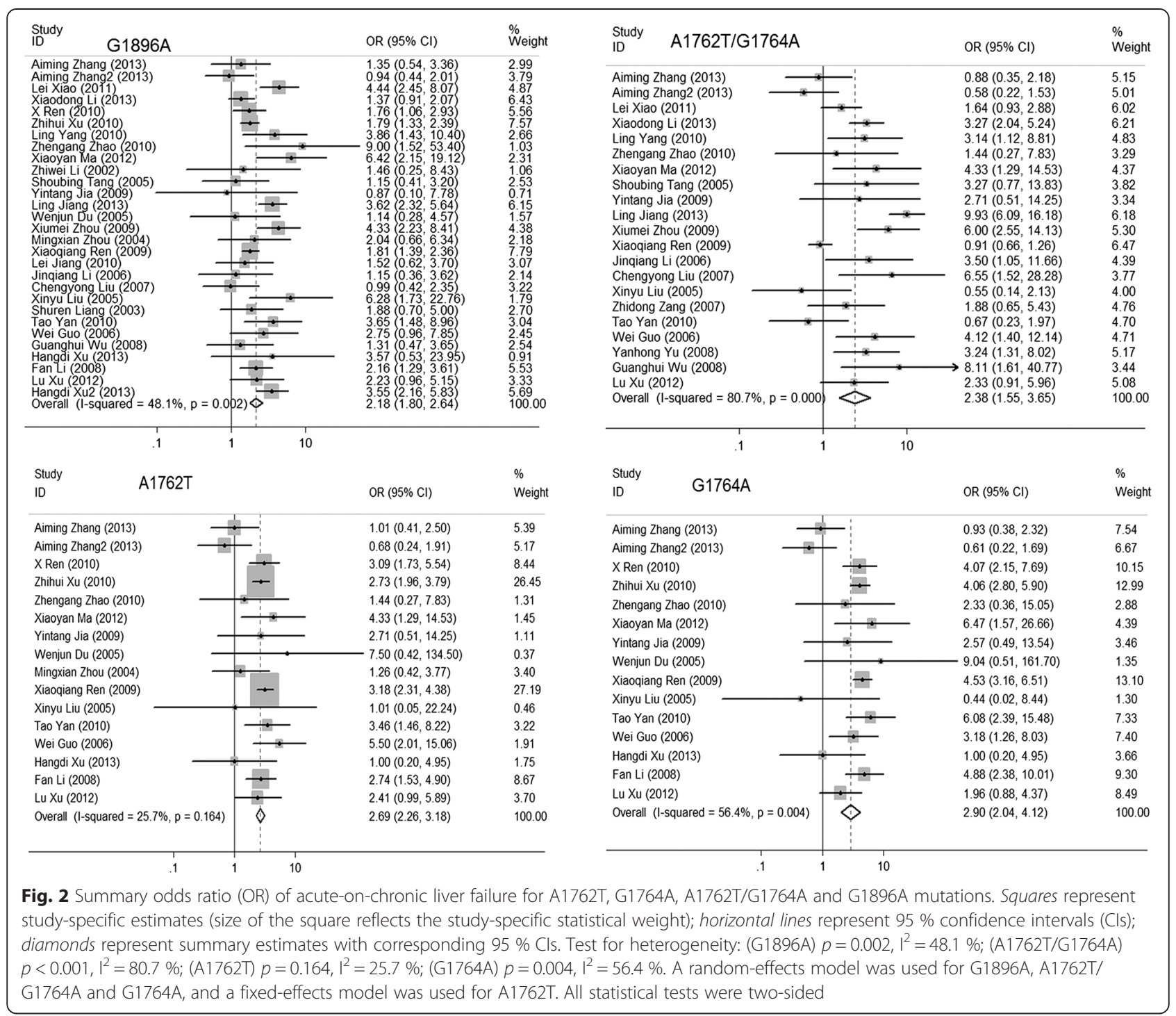

the search strategy was "hepatitis B" [Abstract] AND "mutation" [Abstract]. The inclusion criteria were: 1) studies contained control groups; 2) ACLF diagnosis was based on the APASL criteria, as follows: serum bilirubin $\geq 5 \mathrm{mg} / \mathrm{dl}$ and coagulopathy (INR $\geq 1.5$ or PTA $<40 \%)$ are mandatory. Ascites and/or encephalopathy were determined by physical examination within 4 weeks [38], or the ACLF diagnosis was based on the criteria recommended by the Chinese Society of Infectious Disease and the Chinese Society of Hepatology: HBV infection history; total serum bilirubin $>10 \mathrm{mg} /$ $\mathrm{dl}, \mathrm{PTA}<40 \%$ and recent complications that also meet APASL criteria; 3) BCP or PC mutations were detected; 4) the outcome was ACLF; and 5) ORs and $95 \%$ CIs were shown or could be calculated from original data. Studies without control groups or studies in which patients were co-infected with another hepatitis virus or HIV, with the presence of other underlying chronic liver diseases (such as
Wilson disease and autoimmune hepatitis) or liver cancer were excluded. For studies that contained over-lapping populations, the study containing the larger number of participants or the most recent study was included.

\section{Data extraction}

Feishu $\mathrm{Hu}$ and Sheng Bi extracted information independently as follows: publication year, location, study design, number and subject characteristics, HBV mutations, genotypes, $\mathrm{HBeAg}$ status, variation testing approach and probable confounding factors. All authors discussed results and reached an agreement if there were discrepancies. $\mathrm{BCP} / \mathrm{PC}$ region mutation sites were included. Patients co-infected with wild-type viruses and $\mathrm{BCP} / \mathrm{PC}$ mutated viruses were excluded. Subjects with a single mutation were excluded when assessing A1762T/G1764A double mutations and A1762T/G1764A/G1896A triple mutations. 
Table 3 Pooled unadjusted risk estimates of ACLF after stratification or matching

\begin{tabular}{|c|c|c|c|c|c|}
\hline Mutation site & Matching factor & OR & $\_\mathrm{LCl}$ & $\_\mathrm{UCl}$ & $P$ \\
\hline \multirow[t]{3}{*}{ T1753V } & unmatched & 1.919 & 1.414 & 2.606 & 0.000 \\
\hline & age and sex matched & 1.481 & 0.982 & 2.234 & 0.061 \\
\hline & age, sex, genotype and HBV DNA matched & ND & ND & ND & ND \\
\hline \multirow[t]{3}{*}{ A1762T } & unmatched & 2.685 & 2.264 & 3.185 & 0.000 \\
\hline & age and sex matched & 2.307 & 1.555 & 3.422 & 0.000 \\
\hline & age, sex, genotype and HBV DNA matched & 1.326 & 0.585 & 3.007 & 0.499 \\
\hline \multirow[t]{3}{*}{ G1764A } & unmatched & 2.901 & 2.041 & 4.122 & 0.000 \\
\hline & age and sex matched & 2.023 & 1.013 & 4.041 & 0.046 \\
\hline & age, sex, genotype and HBV DNA matched & 1.310 & 0.555 & 3.094 & 0.538 \\
\hline \multirow[t]{3}{*}{$\mathrm{A} 1762 \mathrm{~T} / \mathrm{G} 1764 \mathrm{~A}$} & unmatched & 2.376 & 1.548 & 3.648 & 0.000 \\
\hline & age and sex matched & 2.602 & 1.270 & 5.333 & 0.009 \\
\hline & age, sex, genotype and HBV DNA matched & ND & ND & ND & ND \\
\hline \multirow[t]{3}{*}{ G1896A } & unmatched & 2.181 & 1.800 & 2.642 & 0.000 \\
\hline & age and sex matched & 2.014 & 1.505 & 2.695 & 0.000 \\
\hline & age, sex, genotype and HBV DNA matched & 1.479 & 1.017 & 2.152 & 0.041 \\
\hline \multirow[t]{3}{*}{ G1899A } & unmatched & 3.525 & 2.882 & 4.312 & 0.000 \\
\hline & age and sex matched & 3.171 & 2.464 & 4.081 & 0.000 \\
\hline & age, sex, genotype and HBV DNA matched & ND & ND & ND & ND \\
\hline \multirow[t]{3}{*}{ C1766 } & unmatched & 1.849 & 1.403 & 2.437 & 0.000 \\
\hline & age and sex matched & 1.719 & 1.226 & 2.411 & 0.002 \\
\hline & age, sex, genotype and HBV DNA matched & ND & ND & ND & ND \\
\hline \multirow[t]{3}{*}{ T1768A } & unmatched & 2.199 & 1.563 & 3.094 & 0.000 \\
\hline & age and sex matched & 2.203 & 1.425 & 3.405 & 0.000 \\
\hline & age, sex, genotype and HBV DNA matched & ND & ND & ND & ND \\
\hline \multirow[t]{3}{*}{ A1846T } & unmatched & 3.163 & 2.157 & 4.639 & 0.000 \\
\hline & age and sex matched & 2.854 & 2.127 & 3.831 & 0.000 \\
\hline & age, sex, genotype and HBV DNA matched & ND & ND & ND & ND \\
\hline
\end{tabular}

$N D$ not determined, $O R$ odds ratio, _LCl low limit of $95 \%$ confidence interval,_UCl upper limit of $95 \%$ confidence interval

\section{Study quality assessment}

Feishu $\mathrm{Hu}$ and Sheng Bi independently evaluated the quality of trials using the NOS, which was developed for case-control studies. Each study that was included was judged on three broad perspectives: selection of study groups, comparability of groups and ascertainment of exposure for case-control studies. Disagreements were resolved by discussion between all authors.

\section{Statistical analysis}

The effect measures were ORs and the corresponding $95 \%$ CIs. Within-study heterogeneity was assessed using Cochrane's Q-test and the $\mathrm{I}^{2}$ test [39]. Summary ORs were pooled by a random or fixed-effect model based on the results of a heterogeneity test. To detect the stability with primary analysis, we conducted a sensitivity analysis using a "leave one out analysis". Publication bias was detected using funnel plots and the Egger test [40].
Significant publication bias was believed to be present if a $\mathrm{p}$ value was less than 0.1 . We also conducted subgroup analysis by stratifying the study participants according to probable confounders such as sex, age, HBV DNA and HBV genotype and we calculated the respective summary risk estimates. We used Stata software (version 12.0; Stata Corp, College Station, TX) to conduct the analysis and to calculate the ACLF summary estimates for the HBV genotype, $\mathrm{HBeAg}$ status and T1753V, A1762T, G1764A, A1762T/G1764A, C1766T, T1768A, A1846T, G1862T, G1896A, G1899A and A1762T/ G1764A/G1896A mutations for ACLF patients. The following mutation sites were also detected in the included studies: G1613A, C1653T, 1752G, T1754V, T1753V/ A1762T/G1764A, T1758C, G1764A/C1766T/T1768A, T1770A, 1773 T, G1775A, C1799V, T1800C, T1803C, G1809T, A1814C, A1837G, A1846G, T1853C, T1858C, G1896A/G1899A, G1896A/G1899A/A1762T/G1764A, 
Table 4 Sensitivity and specificity of single and combined mutations for prediction of ACLF

\begin{tabular}{|c|c|c|c|c|c|c|c|}
\hline Mutation site & $\begin{array}{l}\text { Mutation } \\
\text { status }\end{array}$ & $\begin{array}{l}\text { No. of ACLF } \\
\text { patients }\end{array}$ & $\begin{array}{l}\text { No. of patients } \\
\text { without ACLF }\end{array}$ & $\begin{array}{l}\text { Sensitivity \% } \\
(95 \% \mathrm{Cl})\end{array}$ & $\begin{array}{l}\text { Specificity, \% } \\
(95 \% \text { Cl) }\end{array}$ & PPV & NPV \\
\hline \multirow[t]{2}{*}{$\mathrm{T} 1753 \mathrm{~V}$} & pos & 392 & 397 & 29.3 (26.9 to 31.9) & 83.3 (81.8 to 84.8$)$ & 49.7 (46.1 to 53.2) & 67.8 (66.0 to 69.5$)$ \\
\hline & neg & 945 & 1986 & & & & \\
\hline \multirow[t]{2}{*}{$\mathrm{A} 1762 \mathrm{~T}$} & pos & 872 & 1207 & 74.5 (71.9 to 76.9$)$ & 45.8 (43.7 to 47.9 ) & 41.9 (39.8 to 44.1$)$ & 77.3 (75.0 to 80.0 ) \\
\hline & neg & 299 & 1019 & & & & \\
\hline \multirow[t]{2}{*}{ G1764A } & pos & 921 & 228 & 43.0 (40.9 to 45.1$)$ & 80.6 (78.3 to 82.9) & 80.1 (77.7 to 82.4 ) & 43.7 (41.6 to 45.9$)$ \\
\hline & neg & 1221 & 949 & & & & \\
\hline \multirow[t]{2}{*}{$\mathrm{A} 1762 \mathrm{~T} / \mathrm{G} 1764 \mathrm{~A}$} & pos & 678 & 825 & 51.6 (48.9 to 54.4$)$ & $63.1(61.1$ to 65.1$)$ & 45.1 (42.6 to 47.7) & 69.0 (66.9 to 71.0$)$ \\
\hline & neg & 635 & 1412 & & & & \\
\hline \multirow[t]{2}{*}{ C1766T } & pos & 113 & 118 & 10.3 (8.6 to 12.2 ) & 94.1 (93.0 to 95.1) & 48.9 (42.3 to 55.6) & 65.8 (64.0 to 67.5$)$ \\
\hline & neg & 986 & 1897 & & & & \\
\hline \multirow[t]{2}{*}{ T1768A } & pos & 80 & 64 & 6.9 (5.5 to 8.5$)$ & 96.9 (96.1 to 97.6$)$ & 55.6 (47.1 to 63.8) & 65.1 (63.4 to 66.8) \\
\hline & neg & 1083 & 2020 & & & & \\
\hline \multirow[t]{2}{*}{$\mathrm{A} 1846 \mathrm{~T}$} & pos & 304 & 251 & 54.7 (50.4 to 58.9) & 72.8 (69.8 to 75.6) & 54.8 (50.5 to 59.0$)$ & 72.7 (69.7 to 75.5$)$ \\
\hline & neg & 252 & 670 & & & & \\
\hline \multirow[t]{2}{*}{ G1896A } & pos & 1025 & 1254 & 52.6 (50.4 to 54.8 ) & $65.6(64.0$ to 67.1$)$ & 45.0 (42.9 to 47.0$)$ & 72.1 (70.5 to 73.6$)$ \\
\hline & neg & 924 & 2386 & & & & \\
\hline \multirow[t]{2}{*}{ G1899A } & pos & 323 & 182 & 22.2 (20.1 to 24.4$)$ & 92.7 (91.7 to 93.7) & 64.0 (59.6 to 68.2) & 67.2 (65.6 to 68.8 ) \\
\hline & neg & 1133 & 2325 & & & & \\
\hline \multirow{2}{*}{$\begin{array}{l}\text { G1896A/A1762T/ } \\
\text { G1764A }\end{array}$} & pos & 107 & 135 & 17.6 (14.7 to 20.9) & 87.4 (85.2 to 89.3$)$ & 44.2 (37.9 to 50.7) & 65.1 (62.6 to 67.6) \\
\hline & neg & 500 & 934 & & & & \\
\hline
\end{tabular}

Pos mutation positive, neg mutation negative, PPV positive predictive value, NPV negative predictive value

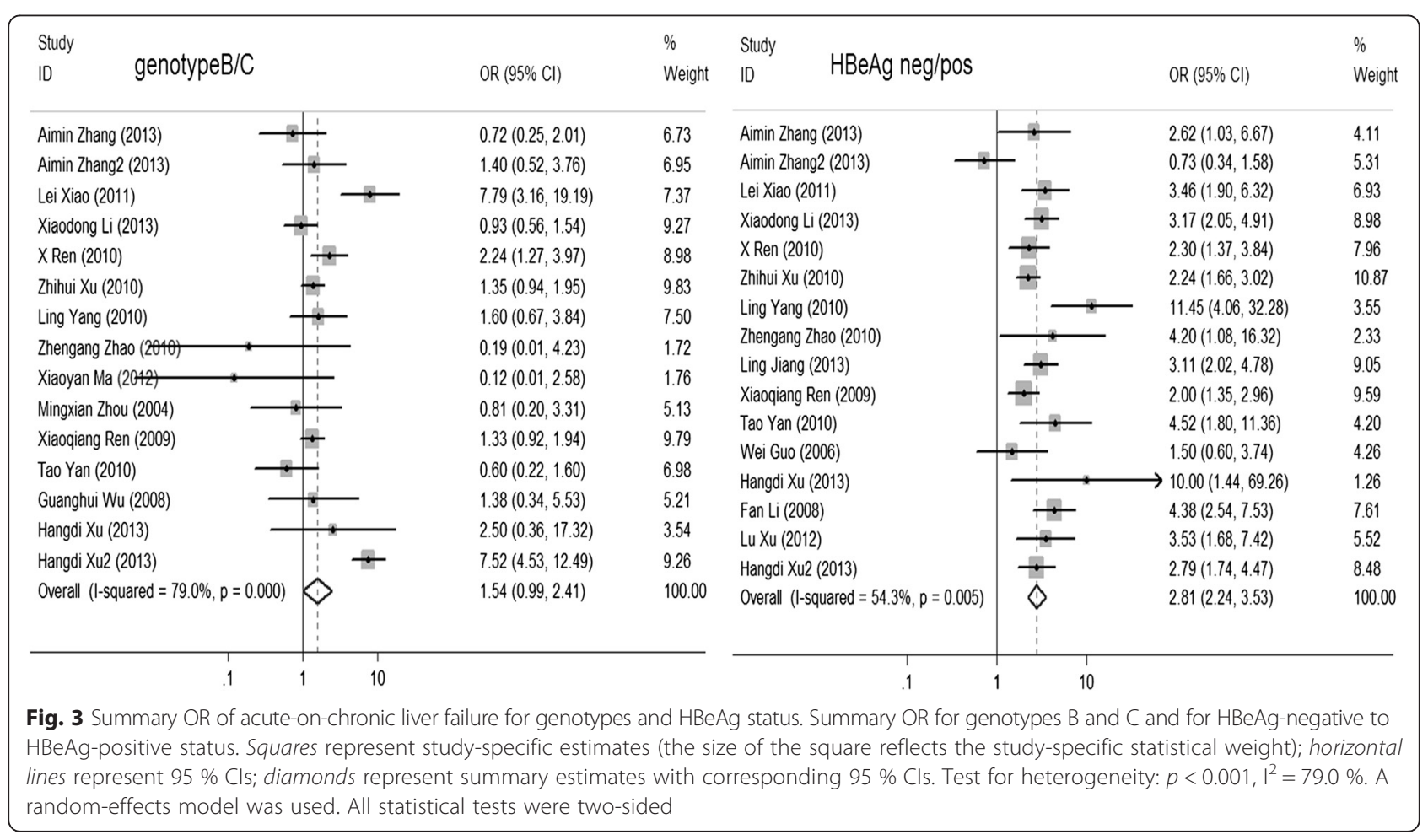


Table 5 Assessment of within-group heterogeneity, publication bias and sensitivity analysis

\begin{tabular}{lccc}
\hline Mutation site & $P$ value for heterogeneity & $P$ value for Egger's test & Sensitivity analysis \\
\hline T1753V & 0.006 & 0.923 & - \\
A1762T & 0.164 & 0.181 & - \\
G1764A & 0.004 & 0.100 & - \\
A1762T/G1764A & 0.000 & 0.455 & - \\
C1766T & 0.852 & 0.300 & - \\
T1768A & 0.681 & 0.291 & - \\
A1846T & 0.037 & 0.856 & - \\
G1862T & 0.001 & 0.125 & + \\
G1896A & 0.002 & 0.520 & - \\
G1899A & 0.307 & 0.591 & - \\
G1896A/A1762T/G1764A & 0.073 & 0.045 & -
\end{tabular}

The summary OR did not change statistical significance when running sensitivity analysis. ' $+{ }^{\prime}=$ the $P$ value for summary OR reached statistical significance of 0.001 when the trial conducted by Xiaoqiang Ren was removed

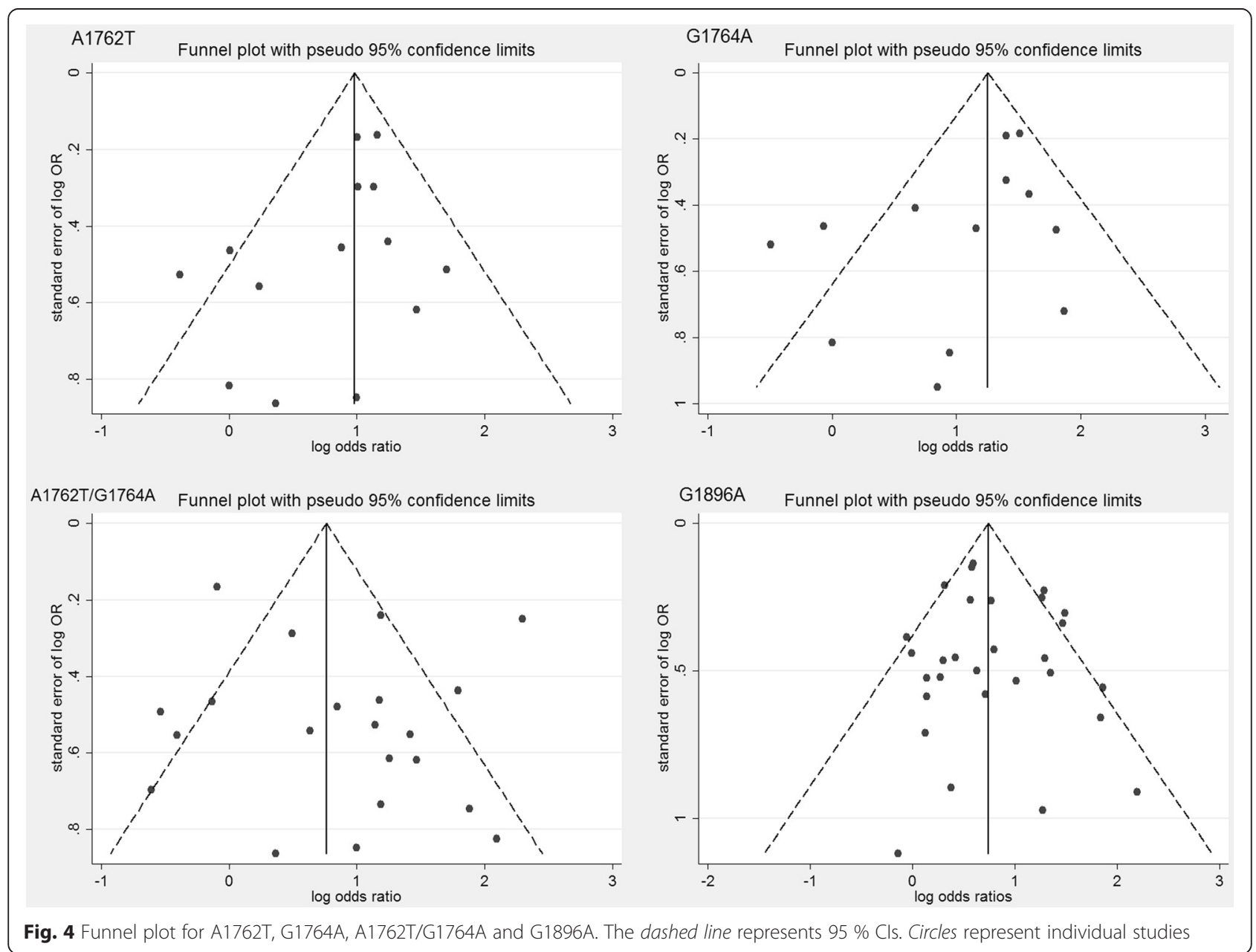


C1913V, 1915A/C, T1938C, A1979G, T1961V and T1753V/A1762T/G1764A/G1896A/G1899A, but they were not included in this meta-analysis because the data was insufficient. Variation frequency between $\mathrm{CHB}$ patients and HBV-ACLF patients was compared using the Chi-squared test. Sensitivity and specificity of HBV mutations for ACLF was evaluated to indicate the possibility of using certain mutations to predict the development of HBV-ACLF.

\section{Additional files}

Additional file 1: Table S1. The Newcastle-Ottawa Scale (NOS) for assessing the quality of the included studies.

Additional file 2: Table S2. Pooled unadjusted risk estimates of ACLF of specific mutation sites.

\section{Competing interests}

The authors declare that they have no competing interests.

\section{Authors' contributions}

$\mathrm{FH}$ participated in the design of the study, performed the literature search, study quality assessment, data extraction, statistical analysis and drafted the manuscript. SB carried out the study design and participated in the literature search, study quality assessment, data extraction, statistical analysis and revised the manuscript. HY participated in the literature search, study quality assessment and data extraction. YS participated in the literature search and data extraction. JS helped design the study and write the manuscript. All authors have read and approved the final manuscript.

\section{Acknowledgements}

We wish to thank our colleagues Zhongkang Ji for critically revising the manuscript; Chenjing Zhang and Jingxin Shao who helped with data acquisition and Wei Chen, Jiajie Zhang, Xiaowei Xue and Zhibo Zhou who were involved in drafting the manuscript.

\section{Author details}

'State Key Lab of Diagnostic and Treatment of Infectious Diseases, Collaborative Innovation Center for Diagnosis and Treatment of Infectious Disease, The First Affiliated Hospital of Medical School, Zhejiang University, Hangzhou 310000, China. ²Department of Hepatology, Ningbo No. 2 Hospital, Ningbo 315010, China.

Received: 16 October 2014 Accepted: 25 May 2015

Published online: 11 June 2015

\section{References}

1. Olson JC, Kamath PS. Acute-on-chronic liver failure: concept, natural history, and prognosis. Curr Opin Crit Care. 2011;17(2):165-9.

2. Sarin SK, Kumar A, Almeida JA, Chawla YK, Fan ST, Garg H, et al. Acute-on-chronic liver failure: consensus recommendations of the Asian Pacific Association for the study of the liver (APASL). Hepatol Int. 2009;3(1):269-82.

3. Liver Failure and Artificial Liver Group, Chinese Society of Infectious Diseases, Chinese Medical Association Severe Liver Diseases and Artificial Liver Group, Chinese Society of Hepatology, Chinese Medical Association. Diagnostic and treatment guidelines for liver failure. Zhonghua Gan Zang Bing Za Zhi. 2006;14(9):643-6.

4. You SL, Rong YH, Zhu B, Zhang AM, Zang H, Liu HL, et al. Changing etiology of liver failure in 3,916 patients from northern China: a 10-year survey. Hepatol Int. 2013;7(2):714-20.

5. Kao JH, Chen PJ, Lai MY, Chen DS. Hepatitis B genotypes correlate with clinical outcomes in patients with chronic hepatitis B. Gastroenterology. 2000;118(3):554-9.

6. Malik A, Singhal DK, Albanyan A, Husain SA, Kar P. Hepatitis B virus gene mutations in liver diseases: a report from New Delhi. PLoS One. 2012;7(6):e39028.
7. Omata M, Ehata T, Yokosuka O, Hosoda K, Ohto M. Mutations in the precore region of hepatitis $B$ virus DNA in patients with fulminant and severe hepatitis. N Engl J Med. 1991;324(24):1699-704

8. Ozasa A, Tanaka Y, Orito E, Sugiyama M, Kang JH, Hige S, et al. Influence of genotypes and precore mutations on fulminant or chronic outcome of acute hepatitis B virus infection. Hepatology. 2006:44(2):326-34.

9. Baumert TF, Rogers SA, Hasegawa K, Liang TJ. Two core promoter mutation identified in a hepatitis B virus strain associated with fulminant hepatitis result in enhanced viral replication. J Clin Invest. 1996;98:2268-76.

10. Tong S, Kim KH, Chante C, Wands J, Li J. Hepatitis B virus e antigen variants. Int J Med Sci. 2005;2(1):2-7.

11. Kay A, Zoulim F. Hepatitis B virus genetic variability and evolution. Virus Res. 2007;127(2):164-7.

12. Fattovich G. Natural history and prognosis of hepatitis B. Semin Liver Dis. 2003;23(1):47-58

13. Chen CJ, Yang HI, Su J, Jen CL, You SL, Lu SN, et al. Risk of hepatocellular carcinoma across a biological gradient of serum hepatitis B virus DNA level. JAMA. 2006;295(1):65-73.

14. Iloeje UH, Yang HI, Su J, Jen CL, You SL, Chen CJ. Predicting cirrhosis risk based on the level of circulating hepatitis B viral load. Gastroenterology. 2006;130(3):678-86.

15. Chu CJ, Hussain M, Lok AS. Hepatitis B virus genotype B is associated with earlier HBeAg seroconversion compared with hepatitis B virus genotype C. Gastroenterology. 2002;122(7):1756-62.

16. Sumi H, Yokosuka O, Seki N, Arai M, Imazeki F, Kurihara T, et al. Influence of hepatitis $B$ virus genotypes on the progression of chronic type $B$ liver disease. Hepatology. 2003;37(1):19-26.

17. Yu MW, Yeh SH, Chen PJ, Liaw YF, Lin CL, Liu CJ, et al. Hepatitis B virus genotype and DNA level and hepatocellular carcinoma: a prospective study in men. J Natl Cancer Inst. 2005;97(4):265-72.

18. Seto WK, Lai CL, Yuen MF. Acute-on-chronic liver failure in chronic hepatitis B. J Gastroenterol Hepatol. 2012;27(4):662-9.

19. Du H, Li T, Zhang HY, He ZP, Dong QM, Duan XZ, et al. Correlation of hepatitis B virus (HBV) genotypes and mutations in basal core promoter/precore with clinical features of chronic HBV infection. Liver Int. 2007;27(2):240-6.

20. Chu CM, Lin CC, Chen YC, Jeng WJ, Lin SM, Liaw YF. Basal core promoter mutation is associated with progression to cirrhosis rather than hepatocellular carcinoma in chronic hepatitis B virus infection. Br J Cancer. 2012;107(12):2010-5.

21. Ranjit C, Syed NK, Jayshree B, Puja S, Shiv KS. Basal core promoter, precore region mutations of HBV and their association with e antigen, genotype, and severity of liver disease in patients with chronic hepatitis B in India. J Med Virol. 2006;78(8):1047-54.

22. Trehanpati N, Hissar S, Shrivastav S, Sarin SK. Immunological mechanisms of hepatitis B virus persistence in newborns. Indian J Med Res. 2013;138(5):700-10.

23. Moradzadeh M, Tayebi S, Poustchi H, Sayehmiri K, Shahnazari P, Naderi E, et al. The possible role of TLR2 in chronic hepatitis B patients with precore mutation. Adv Virology. 2013;2013:780319.

24. Han YP, Li J, Wan YF, Kong LH, Cai J, Dong L, et al. The influence of hepatitis $B$ e antigen on the expression of toll-like receptor 2 on peripheral monocytes. Zhonghua Gan Zang Bing Za Zhi. 2008;16(10):739-42.

25. Zhang AM, Wan ZH, You SL, Liu HL, Zhu B, Chen J, et al. Association of hepatitis B virus mutations of A1846T and $\mathrm{C} 1913 \mathrm{~A} / \mathrm{G}$ with acute-on-chronic liver failure development from different underlying chronic liver diseases. Hepat Mon. 2013;13(9), e12445.

26. Li XD, Liu Y, Xu ZH, Wan ZH, Bai SY, Mao PY, et al. A complete genomic analysis of hepatitis $B$ virus isolated from 516 Chinese patients with different clinical manifestations. J Med Virol. 2013;85:1698-704.

27. Zhao ZG. Study on the relationship between hepatitis B virus mutations and HBV related acute-on-chronic liver failure, Master Thesis. Tianjin China: Tianjin Medical School; 2010.

28. Ma XY, Han T, Pei YZ, Zhao ZG, Gao YT, Li Y, et al. The relationship between hepatitis $B$ virus $P C / B C P$ region mutations and acute-on-chronic liver failure. Chin J Hepatol. 2012;20(9):644-8.

29. Jia YT, Huang T, Liu BF, Song HB, Wu JX. Sequence of basic core promoter and pre-C gene of hepatitis B virus in 130 cases. J Shanxi Med Univ. 2009;40(4):302-7.

30. Jiang L, Xu ZH, Liu Y, Li XD, Xin SJ, Xu DP. Incidences of hepatitis B virus genome C1913A/G mutation in different disease progressions and the effect on viral replication. Chin J Clinicians (Electronic Edition). 2013;7(8):3357-61. 
31. Yuan T-T, Faruqi A, Shih JWK, Shih C. The mechanism of natural occurrence of two closely-linked HBV precore predominant mutations. Virology. 1995;211:144-56.

32. Peijun Y. Clinical study on the relevance between HBV PreS mutations and advanced liver disease, Master Thesis. Kunming China: Kunming Medical University; 2014

33. Qu LS, Liu JX, Liu TT, Shen XZ, Chen TY, Ni ZP, et al. Association of hepatitis $B$ virus pre-S deletions with the development of hepatocellular carcinoma in Qidong, China. PLoS One. 2014;9(5):e98257.

34. Miao FZ, Xu ZH, Liu Y, Li Q, Li XD, Yao WM, et al. Down-regulation effect of HBV genome pre-S deletion mutation on viral replication capacity and the transcriptional activity of the overlapping surface antigen promoter II. Infect Dis Info. 2013;26(6):334-8.

35. Tai P-C, Suk FM, Gerlich W, Neurath R, et al. Hypermodification of an internally deleted middle envelope (M) protein of frequent and predominant hepatitis B virus variants. Virology. 2002;292:44-58.

36. Sun $Z Q, X u Z H$, Ren $X Q$, Liu $Y$, Wang $Y$, Li XD, et al. Affinity analysis of variant forms of $\mathrm{HBV}$ preS/S antigen-specific CTL epitopes in patients with hepatitis B infection. Med J Chin PLA. 2010;35(12):1459-61.

37. Sunbul M. Hepatitis $B$, virus genotypes: global distribution and clinical importance. World J Gastroenterol. 2014;20(18):5427-34.

38. Xu L, Chen EQ, Lei J, Liu L, Zhou TY, Gao Z, et al. Pre-core/basal-core promoter and reverse transcriptase mutations in chronic HBV infected-patients. Hepatogastroenterology. 2012;59(113):212-5.

39. Higgins JP, Thompson SG. Quantifying heterogeneity in a meta-analysis. Stat Med. 2002;21(11):1539-58.

40. Sterne JA, Egger M. Funnel plots for detecting bias in meta-analysis: guidelines on choice of axis. J Clin Epidemiol. 2001;54(10):1046-55.

\section{Submit your next manuscript to BioMed Central and take full advantage of:}

- Convenient online submission

- Thorough peer review

- No space constraints or color figure charges

- Immediate publication on acceptance

- Inclusion in PubMed, CAS, Scopus and Google Scholar

- Research which is freely available for redistribution 